\title{
Evaluation of the functional capacity, respiratory functions and musculoskeletal systems of the children with chest pain for non-cardiac reasons
}

\author{
Arzu Daşkapan ${ }^{1}$, Cihat Şanlı ${ }^{2}$ Saniye Aydoğan-Arslan ${ }^{1}$, Filiz Çiledă̆-Özdemir ${ }^{3}$, \\ Duygu Korkem ${ }^{4}$, Uğurcan Kara² \\ ${ }^{1}$ Department of Physiotherapy and Rehabilitation, Kirkkale University Faculty of Health Sciences, ${ }^{2}$ Division of Pediatric \\ Cardiology, Department of Pediatrics, Kirlkkale University Faculty of Medicine, Kirkkkale; ${ }^{3}$ Department of Physiotherapy \\ and Rehabilitation, Inönü Universty Faculty of Health Sciences, Malatya; ${ }^{4}$ Department of Physiotherapy and Rehabilitation, \\ Üsküdar University Faculty of Healty Sciences, İstanbul, Turkey. E-mail: fztsaniye1982@gmail.com \\ Received:8th December 2016, Revised: 16th February 2017, Accepted: 21st February 2017
}

SUMMARY: Daşkapan A, Şanlı C, Aydoğan-Arslan S, Çiledağ-Özdemir F, Korkem D, Kara U. Evaluation of the functional capacity, respiratory functions and musculoskeletal systems of the children with chest pain for non-cardiac reasons. Turk J Pediatr 2017; 59: 295-303.

Chronic chest pain in healthy children and adolescents generally arises from non-cardiac factors. The purpose of our study was to compare the evaluation results of effort test, respiratory function and musculoskeletal system in children and adolescents with chest pain for non-cardiac reasons with healthy children and adolescents. Physical activity level was determined by the International Physical Activity Questionnaire. The respiratory function test was performed using a spirometer. The posture analysis was performed to determine the upper body deformities. The effort test was performed on a treadmill. The two groups were similar in terms of the physical activity levels, respiratory function and effort test results $(p>0.05)$. The rate of the rounded shoulder, kyphosis was significantly higher in the patient group with chest pain $(\mathrm{p}<0.005)$. Consequently, the musculoskeletal system findings including the pectoralis minor shortness, rounded shoulder, and thoracic kyphosis could have a role in non-cardiac chest pain.

Key words: chest pain, child, musculoskeletal system, respiratory function tests, electrocardiography, effort test, FVC, FEV1, shortness, posture analysis.

Chest pain is a most common symptom which is encountered in pediatrics, pediatric cardiology, and pediatric emergency departments and which threatens life and has an effect on daily life. It is stated that chronic chest pain in healthy children and adolescents generally arises from non-cardiac factors ${ }^{1,2}$. Because of the heterogeneous feature of chest pain which is connected with non-cardiac reasons, there is not a precise classification intended for it. Most of those pains are reported to be possibly related to gastrointestinal and respiratory system problems or psychogenic and idiopathic reasons, especially the musculoskeletal system being in the first place ${ }^{2}$.

The most prevalent reasons for the musculoskeletal-system-based chest pain are muscle and joint dysfunctions which are called musculoskeletal disorders including costochondritis, Tietze's syndrome, sliding rib syndrome, muscle spasm, muscle strain, stress fractures, xiphoid cartilage syndrome and cough trauma ${ }^{3}$. The musculoskeletal-system-based chest pains are defined mostly in the posterior part of the chest (thoracic) wall and it is considered that the segmental dysfunction of the cervico-thoracic spine (C4-T8) causes pain in the front part of the chest wall ${ }^{4,5}$.

Based upon this information, it seems that it is important to extensively evaluate the musculoskeletal system in children and adolescents who have chest pain for noncardiac reasons.

According to the results of the studies 
conducted, it was determined that only $5 \%$ of the chest pain in children and adolescents is cardiac-dependent ${ }^{6-8}$.

The patients with a positive family history, accompanying tachycardia, syncope, decrease in effort capacity, abnormal physical examination, and electrocardiographic findings are required to be evaluated in more detail in terms of cardiac functions.

It is emphasized that what is known about the natural history of chest pain for non-cardiac reasons in children and adolescents and about the risk factors associated with this pain is limited due to the lack of well-designed studies on the subject.

The purpose of our study was to compare the evaluation results of effort test, respiratory function and musculoskeletal system in children and adolescents with chest pain for non-cardiac reasons with healthy children and adolescents.

\section{Material and Methods}

Fifty-seven children and adolescents who applied to Faculty of Medicine, Pediatric Cardiology department with the complaint of chest pain and were diagnosed by the cardiologist with the chest pain for non-cardiac reasons were included in our study. 59 healthy children and adolescents without chest pain were evaluated as the control group.

Children with cooperation problems, chest pain for cardiac reasons, organic heart disease, lung disease, congenital or acquired orthopedic problems were excluded from the study. Within the scope of the evaluation, an informed consent form was received from all the families of all children. As for carrying out the research, the required permission and approval were received from the Ethical Committee of The Clinical Researches in Kirlkkale University. (15/03.12.05.2014). This study was supported by Kirkkale University Scientific Research Projects Coordination Unit .

In the first admission, the nature, severity, and location of the pain, symptoms accompanying the pain, factors triggering, increasing and/ or relieving the pain were examined in detail by the doctor. The socio-demographic characteristics (age, height, weight, body mass index, exercise and smoking habits) of the children and adolescents who participated in the study were noted. In addition, physical activity levels of the participants were determined.

Physical activity level was determined by the International Physical Activity Questionnaire (short form-IPAQ), the Turkish validity and reliability studies of which were performed. The Questionnaire consists of seven questions and provides information about walking, moderately severe activities and the time spent in severe activities, walking and sitting. The calculation of the total score includes walking, moderately severe activity and the time (minutes) and

Table I. Descriptive Characteristics of the Individuals Who Participated in the Study.

\begin{tabular}{llll}
\hline & Patient group $(\mathrm{n}=57)$ & $\begin{array}{l}\text { Control } \\
(\mathrm{n}=59)\end{array}$ & $\mathrm{p}$ \\
\hline Age, mean $(\mathrm{X} \pm \mathrm{SD})$, year & $12.95 \pm 2.70$ & $12.51 \pm 2.92$ & $0.404 \dagger$ \\
BMI, mean $(\mathrm{X} \pm \mathrm{SD}), \mathrm{kg} / \mathrm{m}^{2}$ & $20.38 \pm 6.67$ & $20.19 \pm 4.57$ & $0.859 \dagger$ \\
Gender, n (\%) & & & $0.506 \dagger \dagger$ \\
Female & $25(56.1)$ & $30(50.8)$ & \\
Male & $32(43.9)$ & $29(49.2)$ & \\
Do you smoke? & & & 0.226 \\
Yes & $3(5.1)$ & $3(5.2)$ & \\
No & $54(94.9)$ & $56(94.9)$ & \\
Regular Exercise Habit, n (\%) & & & 0.334 \\
Yes & $10(17.59$ & $12(20.3)$ & \\
No & $47(82.5)$ & $47(79.7)$ & \\
\hline
\end{tabular}

BMI: Body Mass Index

* $\mathrm{p}<0,05$; $\dagger$ : t-test $\dagger \dagger$ : Chi-Square Test 
Table II. Characteristics of the Chest Pain.

\begin{tabular}{|c|c|c|}
\hline \multirow[t]{4}{*}{ Duration of complaining } & Less than 1 week & $7(12.3)$ \\
\hline & 1 week - 1 month & $11(19.3)$ \\
\hline & 1 month - 1 year & $30(52.6)$ \\
\hline & Longer than 1 year & $9(15.8)$ \\
\hline \multirow[t]{4}{*}{ Nature of the pain } & pinprick & $16(28.1)$ \\
\hline & knife stuck & $26(45.6)$ \\
\hline & blunt pain & $13(22.8)$ \\
\hline & burning & $2(3.5)$ \\
\hline \multirow[t]{7}{*}{ Duration of the pain } & shorter than $30 \mathrm{sec}$ & $12(21.1)$ \\
\hline & $30-60 \mathrm{sec}$ & $5(8.8)$ \\
\hline & $1-5 \mathrm{~min}$ & $22(38.6)$ \\
\hline & $5-15 \min$ & $10(17.5)$ \\
\hline & $15-30 \mathrm{~min}$ & $3(5.3)$ \\
\hline & Longer than 30 mins & $4(7.0)$ \\
\hline & cannot be identified & $1(1.8)$ \\
\hline \multirow[t]{5}{*}{ Frequency of the pain } & once a day & $10(17.5)$ \\
\hline & more than once a day & $18(31.6)$ \\
\hline & between $1-5$ in a week & $17(29.8)$ \\
\hline & between $1-5$ in a month & $7(12.3)$ \\
\hline & cannot be identified & $5(8.8)$ \\
\hline \multirow[t]{5}{*}{ Localization of the pain } & left precordium & $34(59.6)$ \\
\hline & right precordium & $5(8.8)$ \\
\hline & sternum & $13(22.8)$ \\
\hline & epigastric & $2(3.5)$ \\
\hline & cannot be identified & $3(5.3)$ \\
\hline \multirow[t]{6}{*}{ Spread of the pain } & to precordium & $7(12.3)$ \\
\hline & to shoulder & $11(19.3)$ \\
\hline & to abdomen & $5(8.8)$ \\
\hline & to arm & $8(14.0)$ \\
\hline & no spread & $26(45.6)$ \\
\hline & Relationship with exercise & \\
\hline \multirow[t]{8}{*}{ Conditions with which the pain is associated } & yes & $43(75.4)$ \\
\hline & no & $14(24.6)$ \\
\hline & relationship with breathing & \\
\hline & yes & $26(45.6)$ \\
\hline & no & $31(54.4)$ \\
\hline & family history & \\
\hline & yes & $28(49.1)$ \\
\hline & no & $29(50.9)$ \\
\hline \multirow[t]{4}{*}{ Resolution } & instinctively & $5(8.8)$ \\
\hline & resting & $16(28.1)$ \\
\hline & other & $25(43.9)$ \\
\hline & no & $11(19.3)$ \\
\hline
\end{tabular}


frequency (days) sum of the severe activity. Sitting score (level of sedentary behavior) is calculated separately. The fact that each activity is performed for at least 10 minutes at once is taken as the criterion in the evaluation of all activities. A score is obtained as "METminute/week" by multiplying the minute, day and MET value (multiples of resting oxygen consumption). The value of 3.3 MET is taken for walking in the calculation of walking score, the value of 4 MET is taken for moderately severe activity, and the value of 8 MET is taken for the severe activity. According to the Questionnaire, physical activity levels are classified as those physically inactive $(<600$ MET-min/week), those with the low physical activity level (600-3000 MET-min/week) and those with the sufficient physical activity level (useful in terms of health) (>3000 MET-min/ week $)^{9}$.

After completing the examinations and taking the history, the respiratory function test was firstly performed by the physiotherapist, chest girth measurements were made, and the effort test was conducted by the cardiologist. A comprehensive musculoskeletal system assessment was also made ${ }^{10}$.

The respiratory function test was performed in a sitting position using a spirometer (BTL-08 Spiro Pro system, Germany). After obtaining at least three measurements which were technically acceptable, the best test was selected for the analysis. Forced vital capacity (FVC), forced expiration volume in the 1st second (FEV1), peak expiratory flow (PEF) and $25-75 \%$ values of the forced expiratory flow (FEF 25$75 \%)$ were noted. The respiratory function test parameters were expressed as the percentage of the values expected by age, height, body weight and gender ${ }^{11}$.

People were positioned in sitting position for chest girth measurements. The measurements were taken from the axillary ( $4^{\text {th }}$ rib alignment)

Table III. Comparison of Physical Activity Levels, Respiratory Function Test, Chest Girth Measurements and Effort Test Results of the Groups.

\begin{tabular}{|c|c|c|c|}
\hline & Patient group & Control & p-value \\
\hline \multicolumn{4}{|l|}{ IPAQ } \\
\hline Severe activity & $510.36 \pm 1193.90$ & $812.61 \pm 1573.36$ & 0.187 \\
\hline Moderately severe activity & $80.00 \pm 187.19$ & $235.63 \pm 739.09$ & 0.326 \\
\hline Walking & $614.67 \pm 706.58$ & $680.59 \pm 884.59$ & 0.578 \\
\hline Total IPAQ & $1226.60 \pm 1467.70$ & $1728.80 \pm 2190.59$ & 0.385 \\
\hline \multicolumn{4}{|l|}{ RFT } \\
\hline Forced vital capacity & $96.73 \pm 17.88$ & $99.29 \pm 16.47$ & 0.285 \\
\hline $\begin{array}{l}\text { Forced expiration volume } \\
\text { in the } 1 \text { st second }\end{array}$ & $94.33 \pm 15.64$ & $93.01 \pm 15.13$ & 0.681 \\
\hline $\begin{array}{l}25-75 \% \text { of the forced } \\
\text { expiratory flow }\end{array}$ & $2.83 \pm 1.07$ & $2.78 \pm 1.05$ & 0.638 \\
\hline Peak expiratory flow rate & $85.80 \pm 19.18$ & $85.33 \pm 17.90$ & 0.892 \\
\hline \multicolumn{4}{|l|}{ Chest girth measurement } \\
\hline $\begin{array}{l}\text { Axillary inspiration- } \\
\text { expiration difference }\end{array}$ & $4.48 \pm 1.85$ & $6.18 \pm 4.52$ & $0.001^{*}$ \\
\hline $\begin{array}{l}\text { Subcostal inspiration- } \\
\text { expiration difference } \\
\text { effort test }\end{array}$ & $2.41 \pm 3.12$ & $4.31 \pm 6.05$ & $0.001^{*}$ \\
\hline $\begin{array}{l}\text { Maximum heart rate } \\
\text { percentage reached }(\%)\end{array}$ & $80.71 \pm 14.78$ & $84.32 \pm 9.26$ & 0.119 \\
\hline MET value reached & $10.30 \pm 2.68$ & $9.89 \pm 2.63$ & 0.795 \\
\hline duration of effort ( $\mathrm{sec}$ ) & $439.37 \pm 123.92$ & $426.20 \pm 164.43$ & 0.820 \\
\hline
\end{tabular}

* $\mathrm{p}<0,05$, IPAQ: International Physical Activity Questionnaire; RFT: The Respiratory Function test; MET: Minimal Energy Consumption 
and subcostal ( $9^{\text {th }}$ rib alignment) regions using a measuring tape at the moment of normal, maximal inspiration and maximal expiration. The measurements were repeated three times, and the highest value was recorded ${ }^{12}$.

For the determination of the cardiovascular endurance, the effort test was performed on the treadmill by performing (ECG) every three minutes accompanied by the pediatric cardiologist according to the Bruce protocol ${ }^{13}$. The maximum heart rate percentage achieved during the effort test, test period and minimal energy consumption (MET) level were noted.

As a part of the musculoskeletal system assessment, the shortness test was performed to pectoralis major and minor muscles in the upper extremity, and the posture analysis was performed to determine the upper body deformities ${ }^{2}$.

\section{Statistics}

Data analysis was performed using SPSS for
Windows Release 16.0 (SPSS Inc, Chicago, USA). The arithmetic mean \pm standard deviation $(\mathrm{x} \pm \mathrm{ss})$ were calculated for all variables. The intergroup differences of the qualitative data were evaluated by the chi-square test. In the intergroup evaluation of the findings, the difference test between 2 averages was applied when parametric conditions were fulfilled, and the Mann-Whitney U Test was applied when parametric conditions were not fulfilled. Error probability was taken as $\mathrm{p}<0.05^{14}$.

\section{Results}

Our study was carried out with 116 children and adolescents aged between 6-18 (average age $12.72 \pm 2.81$ years). The patient group consisting of children and adolescents with chest pain for non-cardiac reasons included 57 individuals and the control group consisting of healthy children and adolescents included 59 individuals. The socio-demographic characteristics of the children and adolescents who participated in

Table IV. Posture Analysis Results.

\begin{tabular}{|c|c|c|c|}
\hline & Patient group $(\mathrm{n}=57)$ & $\begin{array}{l}\text { Control } \\
(\mathrm{n}=59)\end{array}$ & $\mathrm{p}$ \\
\hline Rounded Shoulder, n (\%) & & & $0.001^{*}$ \\
\hline Yes & $47(82.5)$ & $26(44.1)$ & \\
\hline No & $10(17.5)$ & $33(55.9)$ & \\
\hline Kyphosis, n (\%) & & & $0.004^{*}$ \\
\hline Yes & $29(50.9)$ & $15(25.4)$ & \\
\hline No & $28(49.1)$ & $44(74.6)$ & \\
\hline Scoliosis, n (\%) & & & 0.062 \\
\hline Yes & $4(7)$ & $11(18.6)$ & \\
\hline No & $53(93)$ & $48(81.4)$ & \\
\hline Lordosis n (\%) & & & 0.612 \\
\hline Normal & $33(57.9)$ & $34(57.6)$ & \\
\hline Increased & $24(42.1)$ & $24(40.7)$ & \\
\hline Decreased & $0(0)$ & $1(1.7)$ & \\
\hline Chest Type (\%) & & & 0.660 \\
\hline Normal & $50(87,7)$ & $55(93.2)$ & \\
\hline Koilosternia & $2(3.5)$ & $2(3.4)$ & \\
\hline Pigeon Breast & $3(5.3)$ & $1(1.7)$ & \\
\hline Barrel Chest & $2(3.5)$ & $1(1.7)$ & \\
\hline Pectoralis minor muscle shortness $\mathrm{n}(\%)$ & & & $0.001^{*}$ \\
\hline Yes & $44(76.8)$ & $13(22)$ & \\
\hline No & $13(23.2)$ & $46(78)$ & \\
\hline
\end{tabular}

${ }^{*} \mathrm{p}<0,05$; Chi-Square Test 
the study are summarized in Table I.

The characteristics of the chest pain complaint in children and adolescents in the patient group are presented in Table II.

No significant difference was found between the two groups in terms of the physical activity levels and the respiratory function test values ( $p>0.05$, Table III).

When chest girth measurements between the groups were compared, the difference between inspiration and expiration in the axillary and subcostal chest girth measurements in the control group was found to be significantly higher compared to the patient group $(\mathrm{p}<0.05$, Table III).

No significant difference was found between the two groups in terms of the effort test results ( $p>0.05$, Table III).

The postural analysis results according to the groups are presented in Table IV. The rate of the incidence of the rounded shoulder, kyphosis was significantly higher in the patient group with chest pain for non-cardiac reasons compared to the control group $(\mathrm{p}<0.05$, Table IV).

When the muscle shortness results were taken into account, no shortness belonging to the sternal and clavicular part of pectoralis major muscle was found in both groups. However, the rate of the incidence of shortness in the pectoralis minor muscle was significantly lower in the control group compared to the patient group $(\mathrm{p}<0.05$, Table IV).

\section{Discussion}

As a part of our study, children and adolescents with chest pain for non-cardiac reasons were compared with healthy children and adolescents in terms of the comprehensive physical examination and effort test along with the respiratory function tests and musculoskeletal system evaluation results.

It is indicated that one of the most important approaches in evaluating pediatric chest pain is taking a comprehensive history ${ }^{2}$. The sociodemographic characteristics of all children and adolescents who participated in our study were examined in detail. No difference which might be related to the pain symptom in the group with chest pain was encountered between two groups.
It is reported that chest pain in children may result from all the structures comprising the rib cage and included in it, while it is encountered at each age, it emerges most frequently around the age of 13 years ${ }^{15,16}$.

It has been reported that chest pains observed in children and adolescents can usually develop depending on the idiopathic, psychological and musculoskeletal system pathologies without a serious disease $\mathrm{e}^{2,5}$. According to the results of a study carried out, the ratio of musculoskeletalsystem-based pains varies between $21 \%$ and $49 \%$ in children with chest pain ${ }^{17}$. In a study carried out in Turkey, it is stated that the pain arises from the musculoskeletal system in 15\% of 80 children admitted to pediatric polyclinics with chest pain ${ }^{18}$.

Among the distinctive characteristics of musculoskeletal-system-based pain are its being felt in the midsternal area, being in a knife-like stabbing manner, and lasting from a second to a minute ${ }^{19}$. Some characteristics of the pain which gave rise to the thought that the pain might be musculoskeletal-system-based were determined in the cases having complaints of the pain in our study as follows: the pain usually lasted for between 1-5 minutes and was in a knife-like stabbing manner.

The FEV1, FVC values in the respiratory function tests applied to examine the pain in children and adolescents who received a diagnosis of chest pain for non-cardiac reasons better were similar with the healthy control group. When the results of the effort test applied to determine the relation of chest pain with exercises and its probable effect on the exercise capacity were interpreted, the MET values obtained after the test which were close to each other and the durations of the test demonstrated that there was not a difference between the groups in terms of exercise capacity.

It is demonstrated that there is a positive relationship between the physical activity and cardiorespiratory fitness measured objectively in children and adolescents ${ }^{20-22}$. The study of Berntsen et $\mathrm{al}^{23}$. shows that lung functions are better in children with a high physical activity level. Based on the literature, we consider that similar physical activity levels according to the IPAQ results of the two groups in our study may explain the similarity observed in 
the respiratory function test and effort test parameters. On the other hand, it is estimated that the facts that any problem related to cardiac and respiratory diseases is not determined in children who have complaints of chest pain, that the pain complaint is usually observed for a shorter time than 1 year and the pain experience is less than 5 minutes play a role in the similarity of the effort and respiratory function tests.

Since the chest wall is a structure involving various bones and soft tissues together, it is stated that to define the real reason for chest pain in a person is difficult ${ }^{24,25}$. The necessity of a detailed evaluation of the musculoskeletal system in children and adolescents with chest pain for non-cardiac reasons is emphasized. Attention is drawn to the fact that costochondral joints, sternum, costas, thoracic vertebrae and intercostal, paraspinal, trapezius and pectoral muscles are the important areas which should be evaluated by examining with palpation ${ }^{26}$. At the end of our study, the most important differences distinguishing the children with chest pain for non-cardiac reasons from the healthy controls were obtained from the musculoskeletal system evaluations. In the children with chest pain, kyphosis, rounded shoulder problems, and Pectoralis Minor Muscle Shortness rate in both directions were significantly higher when compared to another group.

According to the results of the studies carried out, the postural deformities of the spinal column and shoulder arch are frequently encountered in school students as a result of factors such as the hyper-flexibility of the musculoskeletal system, carrying a heavy bag, writing in wrong posture for a long time and listening to the lesson with the neck, shoulders and waist in a stable bad position ${ }^{27-29}$. In quite an early study, it is expressed that scoliosis and kyphosis are not expected to be the only reason for chest pain. The related deformities are accepted to be predisposing factors in the ligament-based chest pains ${ }^{30}$.

The appropriateness of the shoulder joint and arm position depends on the symmetrical sequence of the scapula bones. When the sequence of the scapula bones is abnormal it causes deformity in the shoulder joint ${ }^{27,31}$.

It is reported that kyphosis contributes to the development of rounded shoulder in students at young ages and it is often encountered together with two spinal deformities ${ }^{32,33}$. The results related to the postural deformities in children with chest pain in our study comply with all the information in the literature.

Kocis ${ }^{34}$ gives a detailed list for different diagnoses in children with chest pain. Pectoralis Major and Minor muscles are the most important muscular pains included within this list. According to Simons 35 , the trigger point with pain of the pectoralis minor muscle imitates cardiac ischemia and it is necessary to regard it as a different diagnosis of chest pain.

The pectoralis minor muscle starts from the exterior surface of the cartilages of the $3^{\text {rd }}$ and $5^{\text {th }}$ costas and attaches to the coracoid process of the scapula. The functions of this muscle are to stabilize the scapula and help inspiration by pulling up the costas that it holds on to when the shoulder is stable. When the pectoral muscles are short, they cause rounded and stoop shoulders, the head-tilt-forward posture and thoracic kyphosis by pulling the shoulder arch to the protraction 36,37 . Furthermore, it is assumed that a shortened Pectoralis Minor muscle may have a relation with the decrease in the upper body mobility ${ }^{38}$.

The double-sided Pectoralis Minor muscle shortness which is a prominent finding in children and adolescents with chest pain is a finding that is expected to accompany two other postural deformities observed, which are kyphosis and rounded shoulders, that may have a role in chest pain and supports the literature. On the other hand, again in line with the literature, the values for the chest girth measurements especially at the subcostal level in children and adolescents with pain are lower. It was thought that the fact that the Pectoralis Minor muscle shortness decreases the stretching ability of the chest might be related to this result.

As a result, it was thought that the musculoskeletal system findings which involve the pectoralis minor shortness, rounded shoulder and thoracic kyphosis in children with chest pain for non-cardiac reasons may have a role in the pain. In addition to the routine examination in children and adolescents with chest pain, it will be possible to determine the postural problems with simple musculoskeletal 
system evaluations and it will be possible to correct them with proper exercise programs. It will be possible to decrease application rates due to chest pain for non-cardiac reasons to pediatric clinics and the workload of pediatrists with an early evaluation and intervention.

\section{REFERENCES}

1. Balfour IC, Rao PS. Chest pain in children. Indian J Pediatr 1998; 65: 21-26.

2. Evangelista JA, Parsons M, Renneburg AK. Chest pain in children: diagnosis through history and physical examination. J Pediatr Health Care 2000; 14: 3-8.

3. Gokhale J, Selbst SM. Chest pain and chest wall deformity. Pediatr Clin North Am 2009; 56: 49-65.

4. Dwyer A, Aprill C, Bogduk N. Cervical zygapophyseal joint pain patterns. I: a study in normal volunteers. Spine 1990; 15: 453-457.

5. Stochkendahl MJ, Christensen HW, Vach W, HøilundCarlsen PF, Haghfelt T, Hartvigsen J. A randomized clinical trial of chiropractic treatment and selfmanagement in patients with acute musculoskeletal chest pain: 1-year follow-up. J Manipulative Physiol Ther 2012; 35: 254-262.

6. Cohn HE, Arnold LW. Chest pain in young patients in an office setting cardiac diagnoses, outcomes, and test burden. Clin Pediatr 2012; 51: 877-883.

7. Fyfe DA, Moodie DS. Chest pain in pediatric patients presenting to a cardiac clinic. Clin Pediatr (Phila) 1984; 23: 321-324.

8. Selbst SM. Chest pain in children. Pediatrics 1995; 75: 1068-1070.

9. Saglam M, Arikan H, Savci S, et al. International physical activity questionnaire: reliability and validity of the Turkish version. Percept Mot Skills 2010; 111: 278-284.

10. Kendall FP, McCreary EK, Provance PG, Rodgers MM, Romani WA. Muscles, Testing and Function, with Posture and Pain. Baltimore: Williams and Wilkins, 1993: 2-65.

11. Johnson JD, Theurer WM. A stepwise approach to the interpretation of pulmonary function tests. Am Fam Physician 2014; 89: 359-366.

12. Bockenhauer SE, Chen H, Julliard KN, Weedon J. Measuring thoracic excursion: Reliability of the cloth tape measure technique, J Am Osteopath Assoc 2007; 107: 191-196.

13. Van Der Cammen-van MH, IJsselstijn H, Takken T, et al. Exercise testing of pre-school children using the Bruce treadmill protocol: new reference values. Eur J Appl Physiol 2010; 108: 393-399.

14. Hayran M, Hayran M. Sağlık araştırmaları için temel istatistik. Ankara: Omega Yayınları, 2011: 155-157.

15. Akalın F. Çocuk ve ergenlerde göğüs ağrısı. Türk Ped Arş 2010; 45: 2-5.

16. Woods WA, McCulloch MA. Cardiovascular emergencies in the pediatric patient. Emerg Med Clin N Am 2005; 23: $1233-1249$.
17. Ayloo A, Cvengros T, Marella S. Evaluation and treatment of musculoskeletal chest pain. Prim Care 2013; 40: 863-887.

18. Şanlı C, Akalın N, Koçak Ü ve ark. Göğüs ağrısı ile başvuran çocuklarda nedenlerin değerlendirilmesi. Turkiye Klinikleri J Pediatr 2006; 15: 46-51.

19. Tunaoglu FS, Olguntürk R, Akcabay S, Oguz D, Gücüyener K, Demirsoy S. Chest pain in children referred to a cardiology clinic. Pediatr Cardiol 1995; 16: $69-72$

20. Brage S, Wedderkopp N, Ekelund U, et al. Features of the metabolic syndrome are associated with objectively measured physical activity and fitness in Danish children: the European Youth Heart Study (EYHS). Diabetes Care 2004; 27: 2141-2148.

21. Gutin B, Yin Z, Humphries MC, Barbeau P. Relations of moderate and vigorous physical activity to fitness and fatness in adolescents. Am J Clin Nutr 2005; 81: 746-750.

22. Andersen LB, Harro M, Sardinha LB, et al. (2006) Physical activity and clustered cardiovascular risk in children: a cross-sectional study (The European Youth Heart Study). Lancet 368: 299-304.

23. Berntsen S, Wisløff T, Nafstad P, and Nystad W. Lung function increases with increasing level of physical activity in school children. Pediatr Exerc Sci 2008; 20: $402-410$

24. Bosner S, Becker A, Hani MA, et al. Chest wall syndrome in primary care patients with chest pain Presentation, associated features and diagnosis. Fam Pract 2010; 27: 363-369.

25. Verdon F, Herzig L, Burnand B, et al. Chest pain in daily practice: occurrence, causes and management. Swiss Med Wkly 2008; 138: 340-347.

26. Winzenberg T, Jones G, Callisaya M. (2015) Musculoskeletal chest wall pain. Aust Fam Physician 2015; 44: 540-544.

27. Akbari A, Gannad R. Prevalence of shoulder postural impairments in 10-12 years old primary students of Zahedan. J Med Sci 2006; 6: 332-337.

28. Korovessis P, Koureas G, Papazisis Z. Correlation between backpack weight and way of carrying, sagittal and frontal spinal curvatures, athletic activity, and dorsal and low back pain in schoolchildren and adolescents. Clin Spine Surg 2004; 17: 33-40.

29. van Gent C, Dols JJ, de Rover CM, Hira Sing RA, de Vet HC. The weight of schoolbags and the occurrence of neck, shoulder, and back pain in young adolescents. Spine 2003; 28: 916-921.

30. Doran DL. Chest Pain: Mechanical and Postural Causes of Chest Pain. Proc. roy. Soc. Med. 1969; 6: 876-880.

31. Dulton M. Manual Therapy of the Spine 1 st. Edn. Philadelphia: McGraw-Hill Company, 2001; 233-248.

32. Shafer RC. The thoracic region. In: R.C. Shafer RC (Ed). Clinical Biomechanic (1st ed), London: Williams and Willkinks, 1983: 344-350.

33. Braun LF. Postural difference between symptomatic man and woman craniofacial pain patient. Arch Phys Med Rehabil 1991; 72: 653-656. 
34. Kocis KC. Chest pain in pediatrics. Pediatr Clin North Am 1999; 46: 189-203.

35. Simons DG, Travell JG, Simons LS. Travell \& Simons' myofascial pain and dysfunction. Upper Half of Body. (2nd ed) Vol 1 Baltimore, MD: Williams and Wilkins; 1999: 801-886.

36. Agur AMR, Dalley AF. Grant's atlas of anatomy. Hong Kong: Lippincott Williams and Wilkins; 2009: 21-31.
37. Morais N, Cruz J. The pectoralis minor muscle and shoulder movement-related impairments and pain: Rationale, assessment and management, Phys Ther Sport 2016; 17: 1-13.

38. Leelarungrayub D. Chest mobilization techniques for improving ventilation and gas exchange in chronic lung disease. Chronic Obstructive Pulmonary DiseaseCurrent Concepts and Practice. 2012: 400. 